\title{
AN IMPLICIT ALGORITHM FOR COMPUTATION OF OVERFLOW IN FLOOD PLAINS
}

\author{
NGUYEN TAT DAC \\ Institute of Applied Mechanics, NCST of Vietnam
}

\section{Introduction}

In the Mekong Delta, annually, flood is one of the three natural factors strongly influenced on agriculture activities and living condition. For a very dense system of rivers, canals and flood plains, mathematical model is the main tool for planning and for computation of flood control scenarios. In recent time high and low flow computation in rivers and canals is good enough for practical purpose, but all existing computer programs in Vietnam, such as VRSAP, KOD, SAL, have dealt with overflow by explicit procedure. Therefore sometimes the oscillation or unstability of solution can not be overcome. This difficulty can be reduced by an implicit algorithm given in this study. The effectiveness of the proposed method can be seen when one has to handle a big problem like the flood situation in the Mekong Delta during 6 months.

\section{Hydraulic computation for rivers}

\subsection{Governing equations}

For gradually varied unsteady flow in rivers and canals it is customary to use the following one-dimensional Saint-Venant system of equations, which consists of a continuity equation and an equation of motion [1]:

$$
\begin{aligned}
& B \frac{\partial H}{\partial t}+\frac{\partial Q}{\partial x}=q \\
& \frac{\partial Q}{\partial t}+\frac{\partial}{\partial x}\left(\frac{Q^{2}}{A}\right)+g A \frac{\partial H}{\partial x}+\frac{g Q|Q|}{A C^{2} R}-B \frac{T}{\delta}=0
\end{aligned}
$$

where: $H=$ water level above a datum, $Q=$ discharge, $B=$ width at the water surface of river cross section including storage averaged for each segment, $A=$ cross section area, $C=$ Chezy number, $g=$ acceleration due to gravity, $R=$ hydraulic radius, $q=q_{1}+P$ : lateral in/out flow to unit length where $P$ is the exchange flow with adjacent plains and $q_{1}$ is pumping or discharging flows, $T=$ 
wind stress over water surface which will be neglected in computation, $\delta=$ water density, $t=$ time and $x=$ distance along the river.

Hydraulic condition at a junction can be described by conservation law of water and if only subcritical flow is considered the equality of water levels in all branches joining at the junction is approximately guaranteed.

\subsection{Schematization of the river network and outline of the computation}

The river network to be modeled is divided into reaches (branches), linked together at nodes (junction). Each branch could be further divided into segment (finite difference element $\Delta x$ ) by grid points or sections. External extremities of the branches are boundaries of the scheme with given water discharge $Q$ or water level $H$. Hydraulic structures, such as dam, sluice, weir could also be incorporated in the system as special river branches with upstream node and downstream node. Along river branches there exist open adjacent plains, of which submerged areas constitute the storage for river branches, and also linked plains which are connected with the river by small water courses, lateral sluices or weir.

The general outline of the numerical method is as follows:

- Applying the Preissmann four point implicit finite difference formulae to equation (2.1) and (2.2) for every segment within each branch.

- Using recurrent formulae to eliminate $H$ and $Q$ at the intermediate grid points, and as a result a linear equation system for water level at all nodes of the whole system is established.

- Finding the solution of obtained equation by any classical method in linear algebra (e.g. Gauss elimination), after that the recurrent formulae is used to compute the water level and discharge at intermediate grid points.

- For the algorithm developed in [2] the water level in the plains and the exchanged discharge between river and plain are computed explicitly with a weighting coefficient at every time step. But hereafter implicit procedure is applied to compute water level in the plains at the same time with water levels at river junctions.

\subsection{Finite difference equations for river segments}

The partial derivatives in (2.1) and (2.2) are approximated within a time step and a space step by well-known Preissman finite difference scheme for any function $f$ as follows [1]:

$$
\begin{gathered}
f \approx \frac{1}{2}\left[\theta\left(f_{i+1}^{n+1}+f_{i}^{n+1}\right)+(1-\theta)\left(f_{i+1}^{n}+f_{i}^{n}\right)\right] \\
\frac{\partial f}{\partial x} \approx \frac{1}{x_{i}-x_{i-1}}\left[\theta\left(f_{i+1}^{n+1}-f_{i}^{n+1}\right)+(1-\theta)\left(f_{i+1}^{n}-f_{i}^{n}\right)\right]
\end{gathered}
$$




$$
\frac{\partial f}{\partial t} \approx \frac{1}{2 \Delta t}\left[\theta\left(f_{i+1}^{n+1}-f_{i+1}^{n}\right)+(1-\theta)\left(f_{i}^{n+1}-f_{i}^{n}\right)\right]
$$

where $f^{n}$ and $f^{n+1}$ are the values of $f$ at moments $t$ and $t+\Delta t$ respectively, $\theta$ is the weighting coefficient $(\theta=0.6667), f_{i}$ denotes the value of $f$ at cross-section numbered $i$.

\subsubsection{Explicit procedure for plain}

As mentioned in [2] if water level in the plain and exchange flow $P$ are explicitly computed or no plain connected to a river segment by substituting (2.3) in to (2.1), (2.2) and neglecting the small terms of second order, relatively with $\Delta f=f^{n+1}-f^{n}$, the following resulting linear equations for a segment $[i, i+1]$ are obtained:

$$
\begin{aligned}
& A 1 \cdot H_{i}+B 1 \cdot Q_{i}+C 1 \cdot H_{i+1}+D 1 \cdot Q_{i+1}=E 1 \\
& A 2 \cdot H_{i}+B 2 \cdot Q_{i}+C 2 \cdot H_{i+1}+D 2 \cdot Q_{i+1}=E 2
\end{aligned}
$$

where $i=j_{1}, j_{2}, \ldots, j_{N-1}$ within a branch which has $N$ sections numbered from $j_{1} \rightarrow j_{N}$. The coefficients $A 1, B 1, C 1, D 1, E 1, A 2, B 2, C 2, D 2, E 2$ are known functions of water levels, discharges and topographic conditions at previous time step $t$. The detailed formulation of the coefficients in (2.4) has been presented in $[3]$.

\subsubsection{Implicit procedure for plains}

Suppose the $k^{\text {th }}$ plain with water level denoted by $Z_{k}$ is connected to the segment $[i, i+1]$ and let $P$ be exchange flow between the plain and the segment, using Taylor expansion the following expression is obtained

$$
P=P^{n+1}\left(Z_{i}^{*}, Z_{k}\right) \approx P^{n}\left(Z_{i}^{*}, Z_{k}\right)+\frac{\partial P^{n}}{\partial Z_{i}^{*}} \Delta Z_{i}^{*}+\frac{\partial P^{n}}{\partial Z_{k}} \Delta Z_{k}
$$

where

$$
Z_{i}^{*}=\frac{H_{i+1}+H_{i}}{2}, \quad \Delta Z_{k}=Z_{k}^{n+1}-Z_{k}^{n}, \mid \Delta Z_{i}^{*}=Z_{i}^{* n+1}-Z_{i}^{* n}
$$

or in this case (2.5) can be rewritten as

$$
P \approx P^{n}\left(H_{i+1}^{n}, H_{i}^{n}, Z_{k}^{n}\right)+\frac{1}{2} \frac{\partial P^{n}}{\partial Z_{i}^{*}} \Delta H_{i+1}+\frac{1}{2} \frac{\partial P^{n}}{\partial Z_{i}^{*}} \Delta H_{i}+\frac{\partial P^{n}}{\partial Z_{k}} \Delta Z_{k}
$$

here indexes $n$ and $n+1$ denote values at moments $t$ and $t+\Delta t$, respectively.

If the same finite difference box scheme (2.3) and the same linerization procedure are applied to $(2.1)-(2.2)$ combined with $(2.6)$ the system (2.4) now is:

$$
\bar{A} 1 \cdot H_{i}+B 1 \cdot Q_{i}+\bar{C} 1 \cdot H_{i+1}+D 1 \cdot Q_{i+1}=\bar{E} 1+R 1 \cdot Z_{k}
$$




$$
A 2 \cdot H_{i}+B 2 \cdot Q_{i}+C 2 \cdot H_{i+1}+D 2 \cdot Q_{i+1}=E 2
$$

where

$$
\begin{aligned}
& \bar{A} 1=A 1-\frac{1}{2} \frac{\partial P^{n}}{\partial Z_{i}^{*}}, \\
& \bar{E} 1=E 1+P^{n}\left(Z_{i}^{*}, Z_{k}\right)-\frac{1}{2} \frac{\partial P^{n}}{\partial Z_{i}^{*}}\left(H_{i+1}^{n}-H_{i}^{n}\right)-\frac{\partial P^{n}}{\partial Z_{k}} Z_{k}^{n}, \\
& \bar{C} 1=C 1-\frac{1}{2} \frac{\partial P^{n}}{\partial Z_{i}^{*}}, \quad R 1=\frac{\partial P^{n}}{\partial Z_{k}}
\end{aligned}
$$

Note that the difference between (2.4) and (2.7) is seen in the first equation. If there is no plain linked to the segment the two systems are the same.

\subsection{Recurrent formulae in double sweep procedure}

For the solution of eq. (2.4) with the algorithm presented in [2] the water level in the plains is explicitly computed, therefore, only water levels at river cross-sections are used for sweep procedure. Hereafter the implicit procedure for water level in the plains is applied, so at the same time, water levels both in the plain and river are presented in the recurrent formulae in double sweep procedure. Two sweep procedures will be applied. The first sweep following the positive direction of each branch constitutes the determination of recurrent coefficients for every internal and external branch.

$$
\begin{aligned}
H_{i} & =p_{i} \cdot Q_{i}+q_{i} \cdot H_{j_{1}}+\chi_{i} \cdot Z_{k}+r_{i}, \\
Q_{i-1} & =t_{i} \cdot Q_{i}+\nu_{i} \cdot H_{i}+m_{i} \cdot H_{j_{1}}+w_{i} \cdot Z_{k}+s_{i} .
\end{aligned}
$$

The recurrence is started with:

$$
p_{j_{1}}=0, \quad q_{j 1}=1, \quad \chi_{j 1}=0, \quad r_{j_{1}}=0
$$

and following the negative direction of a branch the following backward sweep will be

$$
\begin{aligned}
H_{i} & =p_{i}^{+} \cdot Q_{i}+q_{i}^{+} \cdot H_{j_{N}}+\chi_{i}^{+} \cdot Z_{k}+r_{i}^{+}, \\
Q_{i+1} & =t_{i}^{+} \cdot Q_{i}+\nu_{i}^{+} \cdot H_{i}+m_{i}^{*} \cdot H_{j_{N}}+w_{i}^{+} \cdot Z_{k}+s_{i}^{+} .
\end{aligned}
$$

The recurrence is started with:

$$
p_{j_{N}}^{+}=0, \quad q_{j_{N}}^{*}=1, \quad \chi_{j_{N}}^{+}=0, \quad r_{j_{N}}^{+}=0 .
$$

Eqs. (2.8)-(2.9) are formulated with the assumption that there is only one plain connected to one river segment. If there are $K$ plains connected to a segment then 
(2.8) and (2.9) become:

$$
\begin{gathered}
H_{i}=p_{i} \cdot Q_{i}+q_{i} \cdot H_{j_{1}}+\sum_{n=1}^{K} \chi_{i n} \cdot Z_{n}+r_{i} \\
Q_{i-1}=t_{i} \cdot Q_{i}+\nu_{i} \cdot H_{i}+m_{i} \cdot H_{j_{1}}+\sum_{n=1}^{K} w_{i n} Z_{n}+s_{i} \\
H_{i}=p_{i}^{+} \cdot Q_{i}+q_{i}^{+} \cdot H_{j_{N}}+\sum_{n=1}^{K} \chi_{i n}^{+} \cdot Z_{n}+r_{i}^{+}, \\
Q_{i+1}=t_{i}^{+} \cdot Q_{i}+\nu_{i}^{+} \cdot H_{i}+m_{i}^{+} \cdot H_{j_{N}}+\sum_{n=1}^{K} w_{i n}^{+} \cdot Z_{n}+s_{i}^{+}
\end{gathered}
$$

for forward and backward sweeps, respectively. Here $Z$ denotes water level at the plain center and subscripts $n, k$ denote the $n^{\text {th }}$ and $k^{\text {th }}$ plains.

Note that $j_{1}, j_{N}$ correspond to starting and ending numbers of a river branch, respectively.

\section{Hydraulic computation for plains}

Let $Z_{i}$ be water level at the center of the $i^{\text {th }}$ plain. This plain can be connected to another plain or a river segment. The water balance equation written for this plain in the finite difference form is following:

$$
\left(\frac{F}{\Delta t}-\theta \sum_{k} \frac{\partial Q_{i, k}^{n}}{\partial Z_{i}}\right) \Delta Z_{i}=R_{m}+\sum_{k} Q_{i, k}^{n}+\theta \cdot \sum_{k} \frac{\partial Q_{i, k}^{n}}{\partial Z_{k}} \Delta Z_{k}
$$

where: $F=$ submerged surface area of the $i^{\text {th }}$ plain, $Q_{i, k}^{n}=$ exchange flow at moment $t$ with river segment(s) or with adjacent plain(s) numbered $k, R_{m}=$ rainfall; $\Delta f=f^{n+1}-f^{n}$.

Since the plain-river or plain-plain connection is multiform, it is proposed to be schemed by a weir connected between river and plains, that means the exchanged flow is expressed by:

For free flow:

$$
Q_{i, k}=0.386 \cdot \mu \cdot A \cdot H^{1 / 2} \text {. }
$$

For submerged flow:

$$
\begin{gathered}
Q_{i, k}=\mu \cdot A \cdot(H-h)^{1 / 2} \\
h=\min \left(L_{k}, L_{i}\right) ; \quad H=\max \left(L_{k}, L_{i}\right)
\end{gathered}
$$


where $\mu$ is discharge coefficient, $A$ is flow area over weir crest, $L_{k}$ is the water level on river compared to weir crest, $L_{i}$ is the water level on plain compared to weir crest, $Q_{i, k}$ is conventioned positive for the direction from river (or other plain) into the $i^{\text {th }}$ plain.

From practical point of view, in the case of small depth over weir crest the oscillation will appear and in order to avoid this phenomenon it should take into computation the derivative sign change of (3.2) and (3.3) as indicated in [3].

Using (3.2) or (3.3) equation (3.1) can be rewritten in the following form:

$$
\sum_{k=1}^{K} A 3_{k} \cdot Z_{k}+\sum_{m=1}^{M} B 3_{m} \cdot H_{m}+C 3 \cdot Z_{i}=D 3
$$

where $K, M$ are number of plains and number of river cross-sections connected to the $i^{\text {th }}$ plain, respectively; $A 3, B 3, C 3$ and $D 3$ are known coefficients; $Z_{k}, Z_{i}$ are water levels at the center of the $k^{t h}$ and $i^{\text {th }}$ plains, respectively; $H_{m}$ is water level at river cross-section numbered $m$.

\section{Establishment of node and plain equations}

\subsection{For internal branches}

For a branch linking two junctions (nodes) $I$ and $J$, of which cross-sections are numbered from $j_{1}$ to $j_{N}$, one has unknown water levels at two ends $H_{I}, H_{J}$ and junction condition gives $H_{I}=H_{j_{1}}, H_{J}=H_{j_{N}}$.

Therefore the first equation of $(2.10)$ can be rewritten for $i=j_{N}$ :

$$
\frac{1}{p_{j_{N}}}\left(H_{J}-q_{j_{N}} \cdot H_{I}-\sum_{n=1}^{K} \chi_{j_{N} n} Z_{n}\right)=Q_{j_{N}}+\frac{r_{j_{N}}}{p_{j_{N}}}
$$

and similarly the first equation of $(2.11)$ can be rewritten for $i=j_{1}$ as following:

$$
\frac{1}{p_{j_{1}}^{+}}\left(q_{j_{1}}^{+} H_{J}-H_{I}+\sum_{n=1}^{K} \chi_{j_{1} n} Z_{n}\right)=-Q_{j_{1}}-\frac{r_{j_{1}}^{+}}{p_{j_{1}}^{+}}
$$

\subsection{For external (boundary) branches}

The positive direction of external branches has been conventioned outwards, i.e. $\mathbf{I}$ is internal node, and $\mathbf{J}$ is boundary node where $H_{j n}$ or $Q_{j n}$ (or rating curve) is given, therefore, only $H_{I}=H_{j_{1}}$ must be computed. 
If $Q$ is given at boundary: $Q_{j_{N}}=Q_{B}$, then substituting $H_{J}$ from (4.1) into (4.2), after some transformations the resulting expression has the following form:

$$
\frac{1}{p_{j_{1}}^{+}}\left[\left(q_{j_{1}}^{+} q_{j_{N}}-1\right) H_{I}+\sum_{n=1}^{K}\left(q_{j_{1}}^{+} \chi_{j_{N} n}+\chi_{j_{1} n}^{+}\right) Z_{n}\right]=-Q_{j_{1}}-\frac{1}{p_{j_{1}}^{+}}\left[r_{j_{1}}^{+}+\left(p_{j_{N}} Q_{B}+r_{j_{N}}\right) q_{j_{1}}^{+}\right] .
$$

If $H$ is given at boundary $H_{J}=H_{B}$, from (4.2), one can obtain the following expression

$$
\frac{1}{p_{j_{1}}^{+}}\left(-H_{I}+\sum_{n=1}^{K} \chi_{j_{1} n}^{+} Z_{n}\right)=-Q_{j_{1}}-\frac{1}{p_{j_{1}}^{+}}\left(r_{j_{1}}^{+}+q_{j_{1}}^{+} H_{B}\right)
$$

4.3. Equation for water level at nodes (junctions) and water level in the plains

The water balance at each node $I$ leads to the following equation:

$$
\sum_{k=1}^{J V} Q_{j_{N}}^{k}=\sum_{k=1}^{J R} Q_{j_{1}}^{k}+Q_{I}^{*}
$$

where $J V=$ number of branches going towards the node $\mathbf{I}, J R=$ number of branches leaving the node and going to the other node; $j_{N}=$ the last section of the mentioned above branches and $j_{1}=$ the first section of them, $Q_{I}^{*}=$ lateral flow to the node.

Substituting $Q_{j_{N}}$ and $Q_{j_{r}}$ from (4.1) to (4.4) into (4.5) the following so-called node equations are obtained:

$$
a_{J J} H_{J}+\sum_{I=1}^{S} a_{J I} H_{I}+\sum_{I=1}^{S} \sum_{n=1}^{K} b_{J n}^{I} Z_{n}^{I}=Q_{J}^{*}+c_{J} \quad \text { for } J=1, \ldots, L
$$

where $L=$ number of internal nodes; $S=$ number of river branches going from or into the $J^{\text {th }}$ node; $K=$ number of plains connected to each river branche belonging to the node $J ; a_{J I}, b_{J n}$ are components of the coefficient matrix; $Q_{J}^{*}+c_{J}$ : right hand side vector.

For a river system consisting of $L$ internal nodes and $M$ plains one has $L$ equations of (4.6) form for $L+M$ unknowns which are water levels at $L$ nodes and those at center of $M$ plains. For each plain equation (3.4) is added to the system (4.6), so one has $L+M$ equations for $L+M$ unknowns. The coefficient matrix of (4.6) and (3.4) is sparce and its principle diagonal is dominant, therefore to the obtained system of equations any classical method of linear algebra can be 
applied. In order to reduce memory requirement and computer time the method developed by Gupta [4] is used for this study.

Note that besides the normal branches entering or leaving a node, there are also structures linking two nodes I and J. Because $Q_{I}=Q_{J}$ a linear relationship between the water level at two sides $H_{I}, H_{J}$ of the structure has been established and taken part in the equation (4.6). The detailed procedure for the insertion of structure into the river system can be seen in [2].

\section{Conclusion}

In this study an implicit computation of overflow between rivers and flood plains is presented. Using the algorithm the size of the coefficient matrix can be reduced, computer time is shorten. The oscillation and unstability of solution can be overcome even for a very complicated system of canals, rivers and flood plains.

This study is supported in part by the National Fundamental Research Program Coded 3.2.5

\section{REFERENCES}

1. Cung L. A., Holly F. M., Verwey Jr. A. Practical Aspects of Computational River Hydraulics, Pitman Advanced Publishing Program 1980.

2. Nguyễn Tất Đắc. Mô hình toán học không dừng một chiều cho truyền triều và xâm nhập mặn trên hệ kênh sông, Luận án PTS toán lý, 1987.

3. Cunge J. A. Two-dimensional modeling of flood plains, Chapter 17 of Unsteady Flow in Open Channel, Water Resources Publication 1975.

4. Gupta S. K. and Tanji K. K. Computer program for solution of large, sparse, unsymmetric system of linear equations. International Journal for Numerical Method in Engineering, vol. 11, 1977.

Received January 15, 1999

\section{MộT THUẬT TOÁN ẨN ĐỂ TÍNH TOÁN DÒNG LŨ TRÀN}

Cho đến nay các chương trình máy tính ớ Việt Nam dùng thuật toán hiện để tính lũ tràn đồng, mặc dù dòng cháy trong sông tính ẩn. Do mô phóng dòng tràn như dòng qua đập tràn nên có khi nghiệm bị dao động và không ổn định. Trong bài báo trình bày một thuật toán tính ẩn đồng thời mực nước tại các hợp lưu và mực nước tại tâm các ô ruộng. Với thuật toán này ma trận hệ số thưa và nhỏ. Thuật toán của Gupta giúp cho tính toán nhanh và ổn định vì thế có thể sử dụng để giải quyết bài toán lớn và tránh được sự dao động và mất ổn định của nghiệm. 